\title{
Conferências como rituais: mudança na abrangência das propositu- ras geradas durante o I Ciclo de Conferências de Esporte do Estado do Amapá
}

\begin{abstract}
Alexandre Gomes Galindo ${ }^{1}$
1 Doutorando em Sociologia pela Universidade Federal do Ceará; Mestre em Administração pela Universidade Estadual do Ceará; Professor da Universidade Federal do Amapá, Brasil. E-mail: alexandregalindo@bol.com.br
\end{abstract}

RESUM 0: Este estudo tem o propósito de realizar uma análise de como um evento ritualizado (I Ciclo de Conferências de Esporte do Estado do Amapá) apresenta mudança na quantidade e abrangência das proposituras geradas pelos processos participativos realizados desde os níveis municipal, estadual até o federal, através da análise de conteúdo das propostas aprovadas e registradas nos documentos gerados por todas as conferências implementadas no Estado do Amapá e no Documento Final da Conferência Nacional de Esporte, realizada no mês de junho de 2004 em Brasília-DF. As reflexões que se apresentam têm como referência principal a análise sobre as referências documentais produzidas por um amplo processo ritualizado de legitimação de mudança de posicionamento, induzido pelo Governo Federal, quanto à forma de conduzir a gestão nacional do desporto brasileiro. Inicialmente o presente artigo perpassará pela descrição do ciclo de conferências do Estado do Amapá visto como evento ritualizado em suas fases, para depois estabelecer um olhar voltado para as proposituras geradas, em especial no que se refere à abrangência, entendida neste estudo como representativa do nível institucional que seria mobilizado no processo de atendimento das demandas indicadas em cada proposta elaborada. Em seus aspectos conclusivos, o trabalho aponta para algumas implicações decorrentes da perda de "falas" de atores na medida em que suas proposituras são "relidas", gerando construções mais abrangentes que obscurecem as demandas locais ao final de cada etapa do rito de legitimação.

Palavras-chave: Participação Social, Rito, Planejamento Público, Esporte.

Conferences like rituais: change in coverage of the propositions generated during in the First Cycle of Conferences of Sport of the State of the Amapá

ABSTRACT: This study has the purpose to realise an analysis of as an event ritualized (First Cycle of Conferences of Sport of the State of the Amapá) presents change in the quantity and coverage of the propositions generated M unicipal, provincial until the federal, through the analysis of content of the proposals approved and registered in the documents generated by all the conferences implemented in the State of the Amapá and in the Final Document of the National Conference of Sport realised the month of June of 2004 in Brasilia-DF. The reflections that present have like main reference the analysis on the documentary references produced by a wide process ritualized of legitimation of change of positioning, induced by the Federal Government, regarding the form to drive the national gestion of the Brazilian sport. Initially the present article it will happen by the description of the cycle of conferences of the State of the Amapá seen like event ritualized in his phases, for afterwards establish a look gone back for the propositions generated, especially in which it refers to the coverage, understood in this study like representative of the institutional level that would be mobilized in the process 
of attention of the demands indicated in each proposal elaborated. In his conclusive appearances, the work aims for some implications of the loss of "speeches" of actors in the measure in that his propositions are "reinterpreted", generating constructions more comprehensive obscuring the local demands at the end of each stage of the rite of legitimation.

Keywords: Social Participation, Rite, Public Planning, Sport.

\section{CONSIDERAÇÕES INICIAIS}

O esforço institucionalizado de abrir canais de participação social se fez presente com mais intensidade na condução da gestão pública nacional a partir da promulgação da Constituição Federal de 1988, na medida em que foram estabelecidos institutos democráticos prevendo a participação direta de cidadãos no desenvolvimento das políticas públicas.

A partir de então, a participação, somada à descentralização, assumem o papel de eixos direcionadores do processo de democratização da gestão pública brasileira, induzindo ao estabelecimento e promoção de constantes articulações políticas através da interação de um número cada vez mais amplo e diverso de atores que integram a malha social tanto na esfera municipal, quanto na estadual e federal (ROCHA, 2009).

As experiências participativas executadas nos processos de elaboração, implementação e controle das políticas têm apresentado tanto avanços, como limitações em diversos aspectos, dependendo do tipo de instrumento participativo adotado, dos níveis institucionais, das áreas setoriais, das metodologias implementadas, dos atores envolvidos, dentre outros. Entretanto, independente do contexto, a institucionalização de canais de participação social surge como meio de promover a legitimação das políticas públicas implementadas pelo Estado, tanto sobre 0 aspecto consultivo, quanto deliberativo.

Neste cenário, as Audiências Públicas, Conferências, Fóruns, Congressos, ConseIhos, Orçamentos Participativos, Planos Participativos, dentre outros, se apresentam como meios utilizados para reconhecimento e incorporação das falas e demandas dos diversos segmentos da sociedade nos processos de elaboração, execução e controle das políticas, assumindo o papel de ritos de legitimação de poderes, espaços e ações.

O M inistério do Esporte, em 2004, conduziu a integração de diversas conferências nos níveis municipal, estadual e federal, com o intuito de estabelecer as diretrizes da condução das políticas públicas de desenvolvimento do esporte no País. Foram um total de 83 mil pessoas mobilizadas em 873 municípios de 26 Unidades Federativas, envolvendo representantes de uma variedade ampla de segmentos da sociedade (ESPORTE, 2004).

No âmbito setorial, estas conferências municipais, estaduais e nacional podem ser consideradas como sendo a primeira grande experiência de mobilização institucional do esporte, efetivado nos moldes da constituição de 1988, com o propósito de obter subsídios para elaboração de políticas públicas. Neste processo, cada Unidade Fede- 
rativa teve a oportunidade de abrir espaços em seus municípios para discussão com a sociedade sobre as dificuldades, potencialidades e propostas de ação em relação a diversos temas considerados fundamentais na construção de uma Política Nacional de Esporte no início deste século.

Entretanto, mesmo sendo considerado um avanço na perspectiva da construção de uma democracia com graus mais elevados de descentralização e participação, as conferências de esporte realizadas em 2004 também apresentaram peculiaridades que apontam para diferenças na quantidade e na abrangência das propostas geradas pelos atores que participaram dos encontros, variando conforme a etapa correspondente de cada conferência. Esta variação sinaliza a possibilidade de perda de "falas" construídas pelos atores locais, na medida em que suas demandas registradas foram submetidas a novas "releituras" em um nível superior de deliberação institucional.

0 presente trabalho tem o objetivo de observar como um evento ritualizado (I Ciclo de Conferências de Esporte do Estado do Amapá) apresenta mudança na quantidade e abrangência das proposituras geradas pelos processos participativos realizados desde os níveis municipal, estadual até o federal, através da análise de conteúdo das propostas aprovadas e registradas nos documentos gerados por todas as conferências realizadas no Estado do Amapá e no Documento Final da Conferência Nacional de Esporte, realizada no mês de junho de 2004 em Brasília-DF.

Inicialmente a reflexão perpassará pelo ciclo de conferências do Estado do Amapá visto como evento ritualizado em suas fases, para depois estabelecer um olhar voltado para as proposituras geradas, em especial no que se refere à abrangência, entendida neste estudo como representativa do nível institucional que seria mobilizado no processo de atendimento das demandas indicadas em cada proposta elaborada. 0 trabalho, em seus aspectos conclusivos, aponta para algumas implicações decorrentes da perda de "falas" de atores na medida em que suas proposituras são "releitas", gerando construções mais abrangentes que obscurecem as demandas locais ao final de cada etapa do rito de legitimação.

\section{AS CONFERÊNCIAS COMO EVENTO RITUALIZADO: UM OLHAR SOBRE $O$ I CICLO DE CONFERÊNCIAS DE ESPORTE DO ESTADO DO AMAPÁ}

0 esporte como manifestação social sempre esteve presente no desenvolvimento histórico do Brasil desde antes do descobrimento, através das práticas esportivas utilitárias que eram realizadas pelos índios e colonizadores que habitavam o continente. Neste processo de desenvolvimento, o Estado se torna presente como interventor difuso, na fase do Brasil-Império, através de uma perspectiva fundamentada no estabelecimento de obrigatoriedade de algumas práticas dentro de estabelecimentos militares. Após a República, a partir da década de 1920, o Brasil passa a tomar parte de competições internacionais havendo o surgimento de grandes conflitos e impasses relacionados com a organização da prática do esporte nacional, levando o governo do 
Estado Novo a estabelecer em 1941 uma perspectiva regulatória voltada para normatizar amplamente o esporte brasileiro (TUBINO, 2002. p.15-36)

Desde então, até a década de 1980, o Estado manteve uma relação centralizadora e fortemente autoritária no ordenamento da prática esportiva no Brasil e só através da Constituição de 1988 que se estabeleceu um novo ordenamento mais descentralizado e participativo, expressos através do desenvolvimento de um marco regulatório representado pelas Leis Zico, Pelé e Maguito Vilela (BRASIL, 1993a; 1993b; 1998a; 1998b; 2000).

Entretanto, vale destacar que até a realização da I Conferência Nacional em 2004, a participação social na gestão pública do esporte não se apresentava expressamente instituída nos processos de elaboração, implementação e controle da quase totalidade das políticas públicas desenvolvidas nos M unicípios, Estados e na União. Esta Conferência Nacional, coordenada pelo M inistério do Esporte (BRASIL, 2004), foi implementada através da integração de diversas outras conferências, realizadas nas esferas municipais, estaduais e do Distrito Federal, e teve como finalidade obter subsídios visando o estabelecimento de princípios e diretrizes para a elaboração da nova Política Nacional do Esporte e do Lazer.

$\mathrm{Na}$ esfera municipal, foram abertos, em cada Unidade Federativa, espaços para livre participação da sociedade com o propósito de apontar dificuldades e potencialidades sobre 26 sub-temas, bem como propostas de ação referentes aos seguintes eixos temáticos considerados relevantes: 1) Esporte de Alto Rendimento; 2) Esporte educacional; 3) Futebol; 4) Esporte, Lazer e Qualidade de Vida; 5) Direito ao Esporte e ao Lazer; 6) Economia e Negócios; 7) Administração e Legislação e 8) Esporte e Conhecimento.

As realidades coletivamente construídas nestes espaços foram posteriormente submetidas a uma análise, pelos representantes indicados/eleitos entre os presentes nos arranjos municipais, em Conferências Estaduais circunscritas a cada Unidade Federativa, gerando documentos que compuseram o texto-base utilizado como material de trabalho na Conferência Nacional.

0 processo contou com a realização de diversos ciclos de conferências com 873 municípios de 26 Unidades Federativas, envolvendo a mobilização de um montante superior a 83 mil pessoas representantes de diversos segmentos sociais como gestores, administradores públicos e parlamentares; ONGs, movimentos sociais e populares; entidades profissionais, acadêmicas e de pesquisa; trabalhadores; empresários; entidades administradoras do esporte; entidades de prática do esporte e do lazer, dentre outros (ESPORTE, 2004).

No Amapá, este processo foi desenvolvido nos meses de abril a maio de 2004, através do I Ciclo de Conferências do Esporte do Estado, com a realização de 15 Conferências Municipais, envolvendo 1.710 pessoas, e uma Conferência Estadual, com a participação de 221 representantes da sociedade na qualidade de delegados indicados pelos respectivos fóruns municipais (AM APÁ, 2004. p.10). 
A geração das proposições do I Ciclo de Conferências de Esporte do Estado do Amapá, que foram encaminhadas para subsidiar a Conferência Nacional, se caracterizou por um processo de elaboração coletiva através da: a) construção conjunta dos enunciados produzidos pelas manifestações ocorridas nos grupos de Trabalho e nas Plenárias Finais de cada Conferência M unicipal, gerando as quinze Cartas de Proposições M unicipais; b) elaboração de uma síntese das Cartas de Proposições Municipais pela Comissão de Sistematização da Conferência Estadual, gerando a Coletânea-Perfil do Esporte Amapaense sob a Visão M unicipal; c) construção conjunta dos enunciados produzidos pelas manifestações ocorridas nos grupos de Trabalho e na Plenária Final da Conferência Estadual, usando como Texto-Base a Coletânea, gerando a Carta de Proposições Estadual e d) elaboração do Relatório encaminhado ao M inistério do Esporte, pela Comissão de Sistematização utilizando como base a Carta de Proposições Estadual.

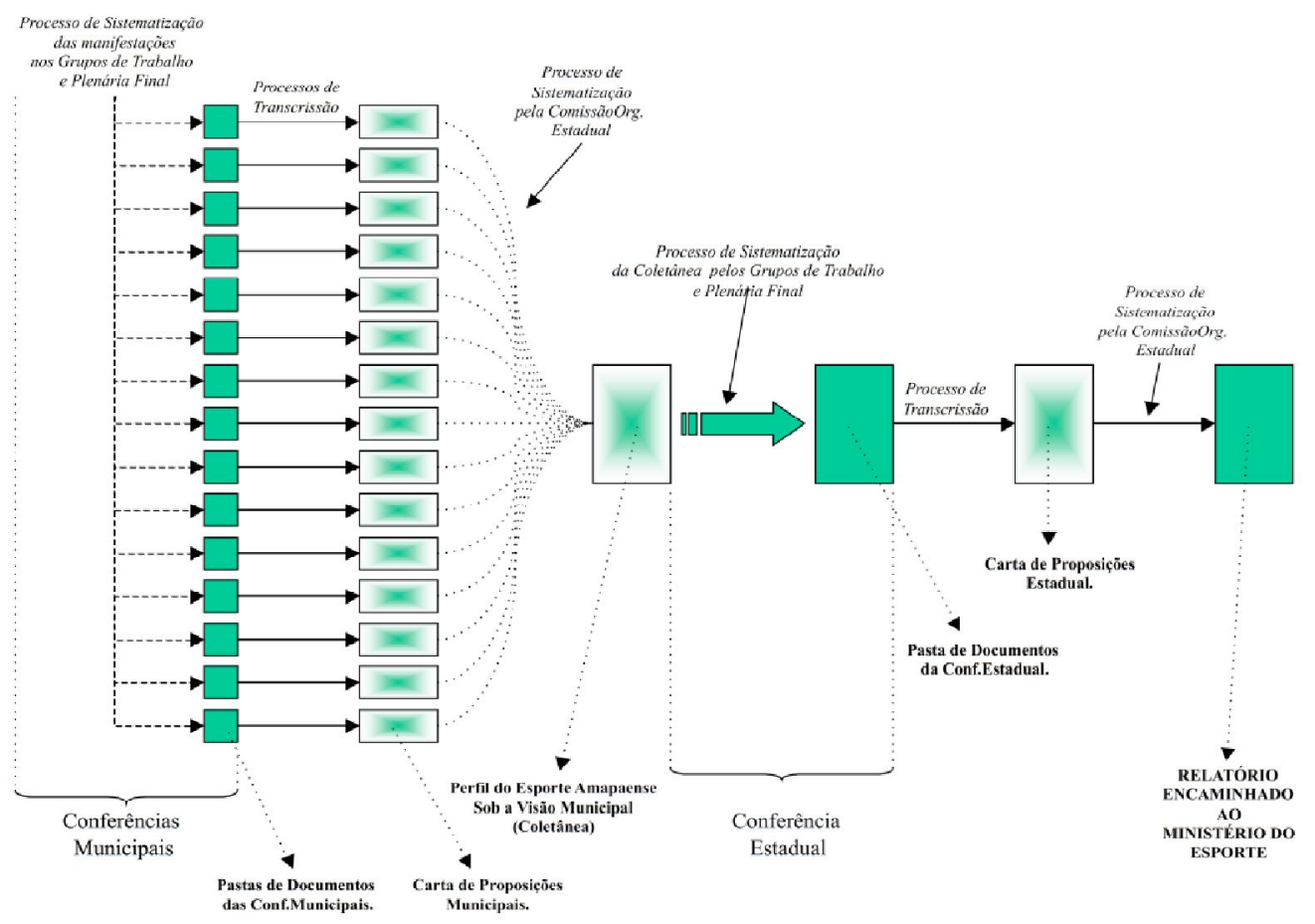

FIGURA 1 - Etapas de confecção do Relatório do I Ciclo de Conferências de Esporte do Estado do Amapá encaminhado ao Ministério do Esporte

Fonte: Amapá (2004)

Visto como rito, a Conferência Nacional de Esporte se apresentou como evento legitimador de uma nova política a ser implementada pelo governo federal através de uma estrutura processual tripartite composta por uma sequência de três momentos distintos. 0 primeiro momento se caracterizou pela ruptura com a normalidade (caracterizada pela mudança nas atividades rotineiras dos envolvidos) e com as práticas cotidianas do fazer (representada pela formação das comissões organizadoras, qualificação das equipes técnicas e preparação da infraestrutura necessária para a concre- 
tização da abertura dos fóruns de diálogo entre o governo e a sociedade). 0 segundo momento, foi representado pelo estado de margem no qual foram realizadas aberturas dos grupos de trabalho e das plenárias finais dos ciclos de conferências municipais, estaduais e nacional (onde ocorreram ritos de construção direta de propostas, marcados pelas manifestações e disputas de opiniões, discursos e interesses daqueles que integraram cada arena de diálogo). 0 terceiro e ultimo momento, se caracterizou como sendo o retorno das atividades cotidianas dos agentes representativos da sociedade e do governo, agora reconfiguradas no sentido de desenvolver ações públicas voltadas à instituição de uma nova política nacional de esporte e lazer após a publicação do Relatório final da Conferência.

O esquema tripartite que, segundo Gennep (1977, p. 30), incorpora as etapas preliminares (separação), liminares (margem) e pós-liminares (agregação), aponta para um processo ritualizado de legitimação de uma mudança de posicionamento do Governo Federal, quanto à forma de conduzir a gestão nacional do desporto brasileiro. Vale destacar, como já previa Gennep em sua obra, que a Conferência Nacional se desdobra em diversos outros eventos ritualizados representados pelas diversas conferências desenvolvidas nos contextos municipais e estaduais.

O I Ciclo de Conferências de Esporte do Estado do Amapá também se enquadra como rito em si, na medida em que a ruptura se fez presente a partir de fevereiro de 2004, no início do processo, através da mudança nas atividades rotineiras de mais de 1.700 pessoas ligadas ao esporte amapaense, bem como pelo estabelecimento e qualificação das comissões organizadoras do estado e dos municípios (abrangendo um total de 116 participantes que, em sua maioria, integravam o corpo administrativo das prefeituras municipais e Departamento Estadual do Desporto e do Lazer). A fase liminar se concretizou pela abertura dos espaços de dialogo entre governo e sociedade civil com a realização das 15 Conferências M unicipais de Esporte e da culminante Conferência Estadual. A volta dos participantes às suas atividades cotidianas como processo pós-liminar de agregação se fez ao final de cada conferência, sendo consumada ao término da Conferência Nacional em junho de 2004.

A identificação dos traços ritualísticos do I Ciclo de Conferências de Esporte do Estado do Amapá pode ser realizada sobre a perspectiva de Turner (1974), na medida em que o Governo composto pelos integrantes da administração pública do Estado assume o papel de transitante (sujeito ritual coletivo), frente a uma liminaridade representativa de um processo de transição (comparada à morte) de um Estado caracterizado por uma indefinição política para um Estado caracterizado por uma nova proposta de Política Nacional de Esporte.

Neste contexto de liminaridade, os representantes da administração pública, considerados tradicionalmente como superiores estruturais que possuem máximo poder, convivem em um ambiente dialético de desenvolvimento em um status diferenciado, caracterizado pelo compartilhamento de poderes com os diversos segmentos da sociedade civil (que se apresentam tradicionalmente como inferiores estruturais), na 
medida em que são instituídos os mecanismos metodológicos de participação e deliberação democráticas nas arenas de diálogo em cada conferência. Conforme identificado por Turner (1977, p. 117-119) estas entidades liminares apresentam qualidades distintas como humildade, passividade, obediência aos condutores do processo, criação de imensa camaradagem e incorporação de uma postura que transparece o desaparecimento e/ ou homogeneização de classes.

Na liminaridade durante o Ciclo de Conferências de Esporte do Estado do Amapá, tanto a construção do Local quanto o recolhimento iniciático e a humilhação iniciática, identificados por Turner (1977, p. 120-125), se fizeram perceber. Na estruturação das Conferências Municipais e Estadual, os locais específicos para acolhimento dos envolvidos foram organizados de tal forma que se pudessem executar metodologias capazes de possibilitar a participação e manifestação direta da sociedade civil, promovendo, em determinados aspectos, a "morte profana" daqueles que assumiam postos de deliberação na estrutura da administração pública. Foi durante os períodos de recolhimento para o planejamento, definição das metodologias participativas e preparação dos ambientes em cada Conferência, que se percebeu maior expressividade na atitude de humildade e reflexão dos componentes das comissões organizadoras, em especial no que se refere aos caminhos mais adequados a serem percorridos para acolher as demandas da sociedade. Na medida em que "poder dos fracos" se manifesta nas arenas de diálogo, a humilhação iniciática se fez perceber nos debates, através das críticas sobre as falhas existentes na condução da gestão pública do esporte, das reivindicações e das demandas apontadas em todos os oito eixos temáticos trabalhados pelos membros da sociedade civil participantes do evento.

Vale destacar que, durante a fase liminar, a natureza espontânea, imediata e concreta da communitas ratificada por Turner (1977, p.152-159) é evidenciada nos Grupos de Trabalho e nas Plenárias do Ciclo de Conferências de Esporte do Amapá, na medida em que ambiências caracterizadas pela mistura de submissão, homogeneidade e camaradagem surgiram com mais expressividade nestes momentos. Enquanto a espontaneidade se fez presente através da livre participação e manifestação dos membros da sociedade civil, a dimensão do imediato se caracterizou pelo registro direto (em formulários) das "falas" coletivamente construídas pelos participantes e a natureza do concreto se fez perceber através das perspectivas pragmáticas das discussões, onde as demandas locais foram frequentemente apresentadas e debatidas.

0 exercício de promoção da participação social, entendida como eixo central no desenvolvimento de políticas públicas, não só é considerado preceito instituído, como também conteúdo pedagógico, "principalmente para a construção de uma ética social que contribua significantemente para o reordenamento da gestão pública e propicie a passagem de uma cultura de favores a uma cultura de direitos" (ROCHA, 2009. p.13). Sobre esta perspectiva, Turner (1977, p. 129) também destaca que a pedagogia da liminaridade, remete aos sujeitos do rito a separarem os vínculos com 0 profano no sentido de evitar "agir somente de acordo com os direitos conferidos ao 
indivíduo pelo exercício do cargo na estrutura social [e] seguir os impulsos psicológicos do indivíduo, à custa de seus companheiros". E é neste ponto que o Ciclo de Conferências se apresentou como evento ritualizado que se propôs também a promover transformações atitudinais voltadas para a mudança de um paradigma de gestão centralizadora para uma nova concepção de gestão participativa na área do esporte no Estado do Amapá.

\section{ABRANGÊNCIA DAS PROPOSITURAS GERADAS NAS DIVERSAS FASES DO CICLO DE CONFERÊNCIAS DE ESPORTE DO ESTADO DO AMAPÁ}

O Ciclo de Conferências de Esporte do Estado do Amapá, realizado em 2004, visto como rito legitimador de natureza consultiva, gerou em seu intermédio (fase liminar) a materialização de documentos utilizados como objetos de referência, representativos da manifestação da sociedade dentro de um processo de contínua construção, perpassando pelas etapas municipais, estadual e culminando na construção do documento final da Conferência Nacional. Os principais documentos legitimados como representativos das "vozes da sociedade" foram as 15 Cartas de Proposições Municipais (aprovadas nas Plenárias Finais de cada respectiva Conferência M unicipal); a Coletânea-Perfil do Esporte Amapaense sob a Visão Municipal (resultado da sistematização das proposições oriundas das Cartas Municipais pela Comissão Organizadora, visando eliminar duplicidades propositivas); a Carta de Proposições Estadual (aprovada na Plenária Final da Conferência Estadual); o Relatório encaminhado ao Ministério do Esporte (com seleção e sistematização das proposições oriundas da Carta Estadual pela Comissão Organizadora, visando atender as determinações do M inistério, o qual solicitava apenas as 10 mais importantes dificuldades e potencialidades em cada subtema e quantidade livre de propostas de ação por eixo temático que pudessem ser discutidas em âmbito nacional) e o Documento final aprovado ao término da Conferência Nacional.

Nas 15 Cartas de Proposições M unicipais, foram registradas 530 dificuldades, 333 potencialidades e 339 propostas de ação. Baseado neste conjunto de enunciados, a Coletânea-Perfil do Esporte Amapaense sob a Visão Municipal, sistematizada pela Comissão Organizadora, incorporou 214 dificuldades, 155 potencialidades e 134 propostas de ação, que serviram de texto-base para as discussões nos grupos de trabaIho e na plenária final da Conferência Estadual, gerando a Carta de Proposições Estadual com 293 dificuldades, 155 potencialidades e 153 propostas de ação. Baseado nesta última Carta, o Relatório enviado ao M inistério do Esporte conteve 138 dificuldades, 90 potencialidades e 57 propostas consideradas como representativas do "oIhar amapaense" a serem integradas com "outros olhares" advindos das outras regiões durante a Conferência Nacional. Ao término, as 39 propostas de ação aprovadas na última Plenária da Conferência Nacional, compuseram o Documento Final apresentado como fruto representativo de um processo coletivo que se propunha orien- 
tar a construção de uma nova política nacional do esporte brasileiro.

Ao comparar os documentos representativos do Ciclo de Conferências, observa-se um padrão similar de redução gradual tanto no número de dificuldades, quanto no número de potencialidades e propostas de ação registradas na medida em que se avança dos primeiros encontros na etapa municipal, para as últimas aprovações na etapa nacional do rito.

GRÁFICO 1 - Número de Dificuldades e Potencialidades registradas nos documentos representativos do I Ciclo de Conferências de Esporte do Estado do Amapá-2004

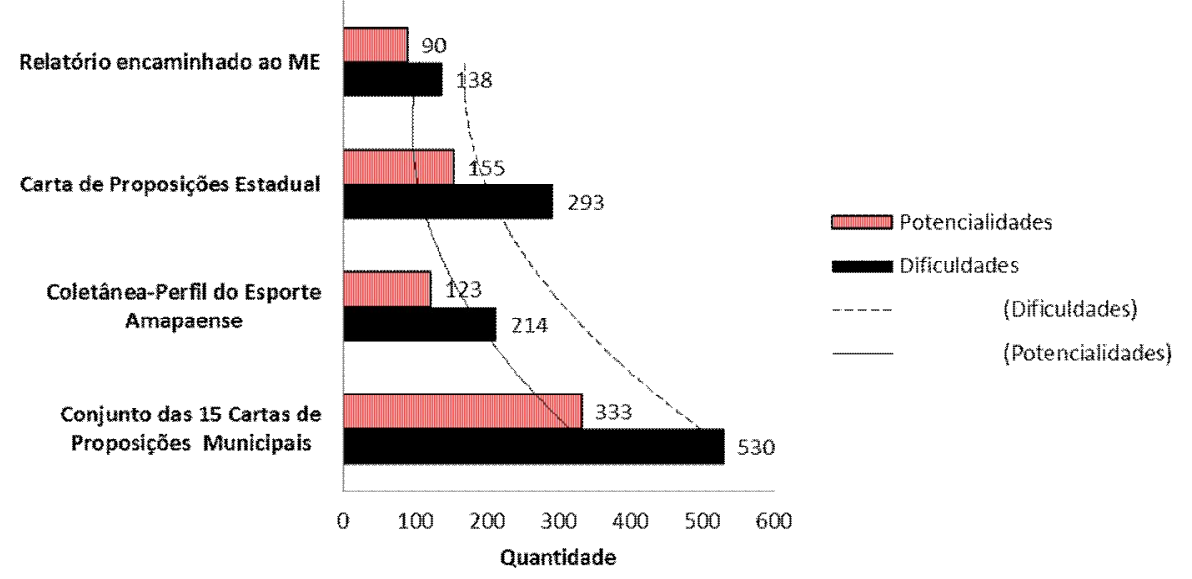

Fonte: Documentos do I Ciclo de Conferências de Esporte do Estado do Amapá (2004)

GRÁFICO 2 - Número de Propostas de Ação registradas nos documentos representativos do I Ciclo de Conferências de Esporte do Estado do Amapá-2004

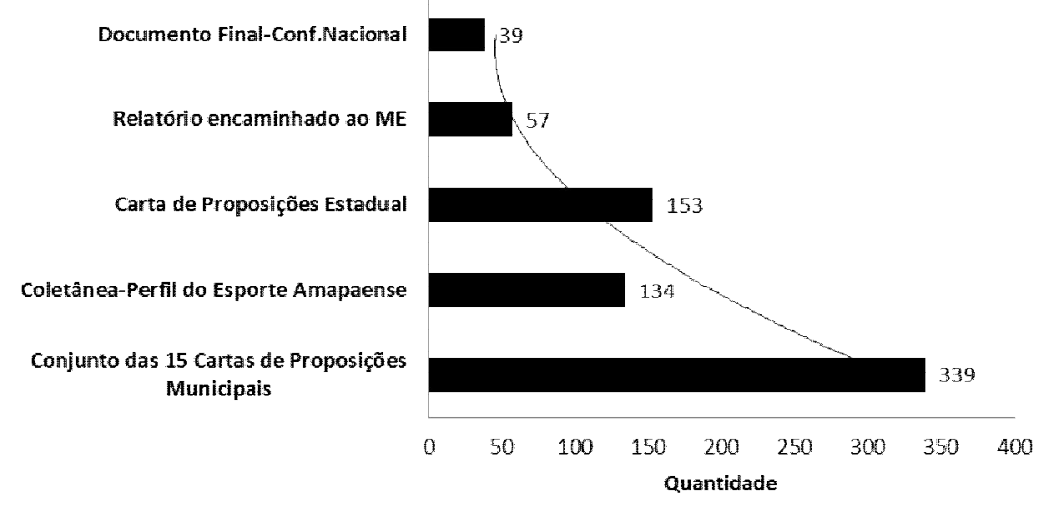

Fonte: Documentos do I Ciclo de Conferências de Esporte do Estado do Amapá (2004)

Esta redução na quantidade de manifestações registradas nos documentos se fez em parte pela indução estrutural do processo, pois as orientações do Ministério do Esporte limitavam o número de enunciados que deveriam ser encaminhados para a Conferência Nacional e sinalizavam aos membros da Comissão Organizadora para, sempre que possível, selecionarem e/ou ajustarem os enunciados de tal nodo que pudessem ser utilizados na Conferência Nacional, com o propósito de elaborar as 
propostas de ação de uma nova política nacional do esporte que deveria estar contida no Documento Final.

Entretanto, a inquietação e estranhamento surgem ao indagarmos sobre a possível perda de "falas" na redução da quantidade e no aumento da abrangência dos enunciados registrados no transcorrer das etapas do Ciclo, pois mesmo sendo um avanço em termos de participação social na elaboração de políticas públicas, as possíveis perdas sinalizam limitações a serem enfrentadas e superadas. Vale destacar que aqui entendemos abrangência como o conjunto dos principais níveis que deveriam provavelmente ser mobilizados no processo de atendimento das demandas indicadas em cada enunciado, podendo ser de natureza restrita, relacionada apenas a um nível de mobilização (municipal, estadual ou federal) ou genérica, relacionada à combinação de dois ou mais níveis de mobilização (municipal/estadual; estadual/federal ou municipal/estadual/federal).

Para observar mais de perto e tornar mais translúcidos alguns elementos relacionados com este estranhamento, foi realizada analise, baseada na estrutura proposta por Bardin (1979), de um corpus definido pelos documentos considerados como representativos do processo (15 Cartas de Proposições Municipais; Coletânea-Perfil do Esporte Amapaense sob a Visão Municipal; Carta de Proposições Estadual; Relatório encaminhado ao Ministério do Esporte e Documento final da Conferência Nacional), envolvendo pré-análise, exploração do material e tratamento dos resultados e interpretações.

0 corpus de trabalho, atendendo aos critérios pré-analíticos de exaustividade, representatividade, homogeneidade e pertinência, permitiu que as Propostas de Ação, estabelecidas como unidades de registro, fossem, na fase de exploração, selecionadas e extraídas do conjunto de documentos, gerando um conjunto de 722 propostas categorizadas por um processo de inventário (processo de "caixa") que as codificou em restritas ou genéricas. Na fase de tratamento foram realizadas as operações estatísticas e os procedimentos de inferência e interpretação tendo em vista a abrangência predominante das propostas de ação elencadas nas diversas etapas do Ciclo de Conferências de Esporte do Estado do Amapá.

Ao total, foram registradas 339 propostas de ação nas Cartas Municipais, 134 na Coletânea, 153 na Carta Estadual, 57 enunciados propositivos no Relatório encaminhado ao M inistério do Esporte e 39 propostas de ação publicadas no Documento Final da Conferência Nacional, classificadas (de acordo com a abrangência de seus enunciados) conforme tabela a seguir: 
TABELA 1- Quantidade absoluta e percentual de Propostas por documento geradas no I Ciclo de Conferências de Esporte do Estado do Amapá

\begin{tabular}{|c|c|c|c|c|c|c|c|c|c|c|}
\hline \multirow[t]{2}{*}{ CATEGORIAS DE PROPOSTAS } & \multicolumn{2}{|c|}{$\begin{array}{l}\text { Cartas de } \\
\text { Proposições } \\
\text { Municipais }\end{array}$} & \multicolumn{2}{|c|}{$\begin{array}{l}\text { Coletânea- } \\
\text { Perfil do Esp. } \\
\text { Amapaense }\end{array}$} & \multicolumn{2}{|c|}{$\begin{array}{l}\text { Carta de } \\
\text { Proposições } \\
\text { Estadual }\end{array}$} & \multicolumn{2}{|c|}{$\begin{array}{c}\text { Relatório } \\
\text { enviado ao } \\
\text { Mi- } \\
\text { nist.Esporte } \\
\end{array}$} & \multicolumn{2}{|c|}{$\begin{array}{c}\text { Documento } \\
\text { Final da I } \\
\text { Conf. Nacio- } \\
\text { nal }\end{array}$} \\
\hline & Quant & (\%) & Quant & (\%) & Quant & (\%) & Quant & (\%) & Quant & $(\%)$ \\
\hline $\begin{array}{l}\text { (RM)-Propostas de natureza restrita } \\
\text { à esfera M unicipal }\end{array}$ & 147 & 43,36 & 13 & 9,70 & 10 & 6,54 & 0 & 0,00 & 0 & 0,00 \\
\hline $\begin{array}{l}\text { (RE)-Propostas de natureza restrita à } \\
\text { esfera Estadual }\end{array}$ & 11 & 3,24 & 12 & 8,96 & 18 & 11,76 & 3 & 5,26 & 0 & 0,00 \\
\hline $\begin{array}{l}\text { (RF)-Propostas de natureza restrita à } \\
\text { esfera Federal }\end{array}$ & 2 & 0,59 & 0 & 0,00 & 4 & 2,61 & 5 & 8,77 & 18 & 46,15 \\
\hline $\begin{array}{l}\text { (GME)-Propostas Genéricas envol- } \\
\text { vendo as esferas Municipal e Esta- } \\
\text { dual }\end{array}$ & 105 & 30,97 & 71 & 52,99 & 73 & 47,71 & 19 & 33,33 & 1 & 2,56 \\
\hline $\begin{array}{l}\text { (GEF)-Propostas Genéricas envol- } \\
\text { vendo as esferas Estadual e Federal }\end{array}$ & 2 & 0,59 & 2 & 1,49 & 5 & 3,27 & 7 & 12,28 & 1 & 2,56 \\
\hline $\begin{array}{l}\text { vendo as esferas M unicipal, Estadual } \\
\text { e Federal }\end{array}$ & 72 & 21,24 & 36 & 26,87 & 43 & 28,10 & 23 & 40,35 & 19 & 48,72 \\
\hline TOTAL & 33 & 100 & 134 & 10 & 15 & 10 & 57 & 100 & 39 & 100 \\
\hline
\end{tabular}

As propostas de natureza restrita à esfera municipal, em sua maioria, sinalizaram a necessidade de: a) identificação e mapeamento dos recursos naturais propícios ao desenvolvimento local de esportes de aventura, bem como qualificação de profissionais para atuarem com estas modalidades; b) qualificação e contratação de um número maior de profissionais de educação física e esporte para atuarem nas escolas locais; c) aumento do intercâmbio esportivo entre os estabelecimentos de ensino locais; d) melhoria da infra-estrutura das escolas locais e de logradouros para a pratica esportiva; e) reformas específicas de estádios e campos, bem como fortalecimento das escolinhas, clubes e ligas locais para a prática do futebol, inclusive no que se refere ao futebol feminino; f) criação de Secretarias M unicipais de Esporte e Lazer para desenvolver políticas voltadas para a promoção da qualidade de vida dos cidadãos e g) apoio, por parte do poder público local, para o aumento da prática esportiva por parte das mulheres.

As propostas de natureza restrita à esfera estadual apontaram para a necessidade do Departamento Estadual do Desporto e do Lazer do Amapá (na época em fase de transformação de Departamento para Secretaria Estadual) desenvolver ações efetivas no sentido de se tornar mais presente nos municípios através: a) do deslocamento de um número maior de profissionais para atuarem nas diversas localidades; b) da realização de qualificações e capacitações para os profissionais, inclusive apoiando a abertura de cursos de Educação Física no Estado e c) da criação de fundo específico destinado a promover apoio financeiro ao desenvolvimento de atletas e profissionais do esporte.

Enquanto as propostas registradas de natureza genérica, envolvendo as esferas municipal e estadual, sinalizaram para o estabelecimento de parcerias voltadas ao 
desenvolvimento de políticas integradas, com propósito de incentivar a prática de atividades físicas e esportivas pelos cidadãos nos municípios, as propostas genéricas, envolvendo as esferas estadual e federal, sugeriram políticas voltadas para: a) estabelecimento de bolsas de estudo e de trabalho (Bolsa de Atleta e de Apoio ao Profissional); b) estabelecimento de intercâmbios esportivos Nacionais e Internacionais; c) construção de instalações para criação de laboratórios de pesquisa em ciência do esporte no Estado; d) realização de ações com o propósito de apoiar a criação de Tribunais de Justiça Desportiva para atender o Sistema Nacional de Esporte; e) fortalecimento do esporte universitário e f) criação de auditorias operacionais para acompanhamento dos projetos financiados por estes dois entes federativos.

As propostas genéricas, que pressupunham o envolvimento dos três níveis (municipal, estadual e federal) no atendimento das demandas indicadas em seus enunciados, apontaram para alternativas de fomento, desenvolvimento e implementação de políticas integradas de: a) incentivo à prática de atividades físicas e desportivas pelos cidadãos (incluindo também campanhas de conscientização) e b) estabelecimento de marcos regulatórios que possam garantir aporte financeiro aos programas, projetos e ações desenvolvidos no Estado.

Sob a perspectiva das propostas de natureza restrita à esfera federal, destacaramse em especial as sugestões visando: a) a criação de um Sistema Nacional do Esporte e do Lazer, b) o estabelecimento de Marcos regulatórios, no âmbito federal, que viabilizem a descentralização e a fiscalização na utilização dos recursos públicos destinados ao esporte e c) a fixação legal de cotas de recursos públicos federais orçamentários para a execução de políticas públicas na área do esporte.

Na medida em que os documentos analisados representam também fases sequenciadas do rito, algumas evidências merecem elucidação, em especial no que diz respeito à mudança na abrangência das proposituras geradas durante o decorrer da etapa liminar, iniciada com a elaboração das Cartas Municipais e finalizada com a aprovação das 39 propostas contidas no Documento Final da Conferência Nacional. Sobre este aspecto, ao ser utilizado como ponto análise o percentual de ocorrências das categorias de propostas em relação a cada documento gerado, puderam-se observar comportamentos diferenciados durante o transcorrer do Ciclo de Conferências. Enquanto, algumas categorias de propostas apresentaram redução gradativa no percentual de ocorrência no decorrer do Ciclo, outras categorias apresentaram aumento gradativo neste percentual e, em alguns casos, houve nítido aumento com posterior redução dos enunciados propositivos em determinadas categorias, conforme se pode verificar no gráfico a seguir. 
GRÁFICO 3 - Abrangência das Propostas de Ação contidas nos documentos do I Ciclo de Conferências de Esporte do Estado do Amapá-2004

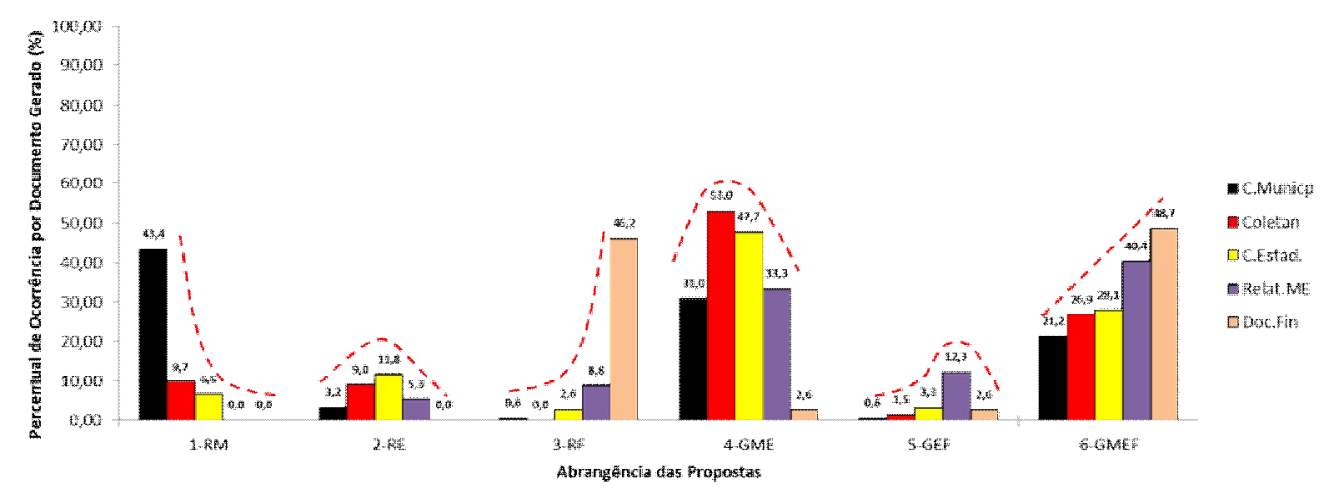

Legenda:

(1-RM) Propostas de natureza restrita à esfera M unicipal; (2-RE) Propostas de natureza restrita à esfera Estadual; (3-RF) Propostas de natureza restrita à esfera Federal; (4-GME) Propostas Genéricas envolvendo as esferas Municipal e Estadual; (5-GEF) Propostas Genéricas envolvendo as esferas Estadual e Federal; (6-GMEF) Propostas Genéricas envolvendo as esferas M unicipal, Estadual e Federal.

(C.M unicp) Cartas de Proposições M unicipais; (Coletan) Coletânea-Perfil do Esp. Amapaense; (C.Estad) Carta de Proposições Estadual; (Relat.ME) Relatório enviado ao Ministério do Esporte; (Doc.Fin) Documento Final da I Conferência Nacional.

Fonte: Documentos do I Ciclo de Conferências de Esporte do Estado do Amapá (2004)

A incorporação de propostas com abrangência restrita à esfera municipal foi mais expressiva no início do Ciclo de Conferências, durante a composição das Cartas Municipais, havendo acentuada redução na medida em que os produtos gerados nos espaços de construção coletiva se deslocavam para esferas institucionais mais elevadas. 0 inverso ocorre com as propostas cuja abrangência se caracterizou como restrita à esfera federal, havendo quase nenhuma ocorrência no início do processo e se tornando expressiva no Documento Final aprovado pela Conferencia Nacional. As proposituras cuja abrangência se restringia à esfera estadual tiveram mais expressividade na composição dos registros contidos na Coletânea, que serviu como Texto-Base da Conferência Estadual, e na Carta de Proposições Estadual.

Este fato nos remete a indagar sobre os elementos indutores vinculados ao processo de elaboração dos enunciados propositivos no Ciclo de Conferências, na medida em que a maior expressividade das propostas com abrangência restrita à esfera municipal, estadual e federal, ocorreu nos documentos trabalhados respectivamente nas conferências municipais, estadual e nacional. Na perspectiva do rito, por mais que tenham sido percebidas várias qualidades características das entidades liminares (humildade, passividade, obediência, camaradagem, dentre outras), e percebido também a manifestação do "poder dos fracos", faz-se necessário destacar que a dimensão política (entendida como um microcosmo específico diferenciado de outras dimensões como religiosa, artística e literária) é nuclear neste tipo de evento, sendo determinante na condução e no delineamento de suas propriedades e dinâmicas.

Sobre este aspecto, a perspectiva de campo político apresentada por Bourdieu 
(2007, 2011) nos remete a levar em consideração que o processo coletivo de elaboração das propostas no Ciclo de Conferências se efetivou dentro de um campo de forças e de lutas, representado pela disputa de ideias e poderes entre vários agentes possuidores de "armas", capitais políticos e poderes simbólicos desiguais, cuja conduta foi determinada pelas posições que estes agentes ocuparam na estrutura de relações de forças no próprio campo em cada momento. Neste contexto, enquanto os atores locais exerceram profunda influência durante a elaboração dos enunciados propositivos de abrangência restrita à esfera municipal, os representantes da comissão organizadora, professores de educação física vinculados à rede estadual de ensino e integrantes das entidades estaduais de administração esportiva tiveram participação ativa na construção dos enunciados propositivos de abrangência restrita à esfera estadual. No final do processo, a comissão organizadora da Conferência Nacional em conjunto com diversos outros atores participaram ativamente na elaboração das proposições contidas no Documento Final cuja abrangência era circunscrita à esfera federal.

0 mesmo processo de conjugação de forças e lutas se fez notar no que diz respeito às proposições genéricas que remetem a necessidade de ações integradas, parcerias e/ ou corresponsabilidades entre os entes federados. Enquanto, a maior proporção de registros de proposituras vinculadas às ações integradas entre as esferas municipal e estadual ocorreu no Texto-Base e na Carta de Proposições da Conferência Estadual, a maior proporção de registros de proposituras vinculadas às ações integradas entre as esferas estadual e federal esteve presente no Relatório encaminhado ao Ministério do Esporte. Sobre a perspectiva do rito, pode-se associar este comportamento ao efeito do "poder dos fracos" sobre os documentos gerados, na medida em que a Carta de Proposições Estadual e o Relatório encaminhado ao Ministério do Esporte incorporam e sinalizam para os integrantes da estrutura de governo (respectivamente das esferas estadual e federal) as demandas de parceria e integração apontadas pelos representantes da sociedade oriundos dos diversos municípios amapaense (no caso da Carta de Proposições Estadual) e pelos membros da comissão organizadora vinculados à administração pública do Estado do Amapá (no caso do Relatório encaminhado ao M inistério do Esporte).

Já, o aumento gradual das proposituras genéricas que remetem a necessidade de ações conjuntas entre as três esferas (municipal, estadual e federal), ao mesmo tempo em que denota certo grau de consenso sobre a importância da integração e descentralização na elaboração, implementação e controle de políticas públicas, apresentam também traços que indicam ter ocorrido o exercício do jogo de poder dentro do campo político.

Enquanto, as propostas genéricas, contidas no Relatório encaminhado ao Ministério, e nos documentos precedentes, estavam voltadas principalmente para o enfrentamento integrado de demandas locais e regionais, as proposituras contidas no Documento Final indicaram predominantemente caminhos para instituir a Política Na- 
cional do Esporte e do Lazer integrado e amparado em marcos regulatórios que garantissem o financiamento e controle dos gastos públicos destinados ao esporte. Sobre este aspecto, evitando fazer julgamentos comparativos de mérito das propostas, vale destacar as observações de Souza (2011, p. 163) no que diz respeito aos cuidados e atenções necessárias sobre os diferentes momentos e locais de produção dos discursos nos processos de planejamento público, na medida em que

“'Dizer a última palavra' ou 'ter a palavra final' significa, em várias línguas, decidir. [e] No Planejamento promovido pelo Estado, sabe-se que quem diz a última palavra, normalmente não são os pobres, os do 'andar de baixo', mesmo quando constituem a esmagadora maioria e mesmo na maior parte das vezes em que lhes é dada a chance de 'participar' [...]".

Tendo como base as evidências explicitadas, convém tecer algumas inferências relacionadas à dimensão global do I Ciclo de Conferências de Esporte do Estado do Amapá como rito legitimador de natureza consultiva. Inicialmente, vale destacar que 0 rito proporcionou a legitimação dos interesses dos agentes integrantes da esfera federal de governo, na medida em que contribuiu para geração de um produto (Documento Final), considerado como fruto de um processo de construção coletiva de propostas, com significativa participação social, elencando sugestões para o estabelecimento de uma nova Política Nacional do Esporte e do Lazer, que estava posta como meta desde o início do ciclo (BRASIL, 2004). Mesmo havendo avanços e limitações, apontados por Terra et al. (2009), Castelan (2011) e Araújo (2013), no processo de desdobramento proveniente da realização da I Conferência Nacional, não se torna difícil identifica-la como evento demarcador da passagem para uma nova gestão pública conduzida pelo M inistério do Esporte.

Entretanto, os documentos transitórios produzidos durante o I Ciclo de Conferências perderam força na medida em que se avançava na direção da elaboração do Documento Final. As cartas M unicipais, a Coletânea, a Carta Estadual e o Relatório encaminhado ao M inistério do Esporte perderam relevância no campo político representado pelo conjunto de elementos que compuseram as últimas arenas de diálogo na Conferência Nacional. Vale ressaltar que a dinâmica do rito só estabelecia formalmente para cada documento a função de ser utilizado como subsídio na elaboração coletiva das dificuldades, potencialidades e propostas de ação na etapa subsequente, sendo estas submetidas a uma nova releitura e reconfiguração. Desta forma, as propostas que inicialmente apontavam para o enfrentamento de demandas específicas locais, foram gradativamente obscurecidas pela priorização de propostas mais genéricas com o avanço das etapas no Ciclo de Conferências, promovendo "perda de falas" e "invisibilidades" durante o processo.

Devido à riqueza contida em cada documento, pois representam produtos coletivamente elaborados que simbolizam olhares específicos sobre as demandas sociais de determinada realidade, torna-se adequado aos agentes integrantes do poder go- 
vernamental, em especial nas esferas municipais e estadual, incorporá-los sempre que possível em seus processos locais de elaboração do planejamento público, conforme já sinalizavam Galindo e M oraes (2004), ao apontarem para a importância destas informações no estabelecimento do escopo das políticas públicas de esporte no Estado do Amapá.

\section{CONSIDERAÇÕES FINAIS: “PARA ONDE VAI NOSSA FALA”}

0 presente estudo propôs tecer algumas observações sobre como um evento ritualizado de natureza consultiva (I ciclo de Conferências de Esporte do Estado do Amapá) apresenta alterações na abrangência das propostas contidas nos documentos legitimados como representativos das "vozes da sociedade". Este processo se desenrolou em pleno campo político (caracterizado por disputas de ideias e poderes entre atores com capitais políticos diferenciados) e a construção coletiva de propostas para elaboração das políticas públicas, vista como rito legitimador, apresentou resultados que refletiram as relações de poderes existentes em cada etapa através dos documentos gerados durante o evento.

Conforme as evidencias observadas, o I Ciclo de Conferências de Esporte do Estado do Amapá apresentou características que sinalizam ter havido: a) abertura de espaços de participação para sociedade contribuir com propostas, através de uma ampla consulta, para elaboração de políticas públicas na área do esporte; b) a incorporação de sugestões da sociedade, sobre propostas de ação, no estabelecimento de uma nova Política Nacional do Esporte e do Lazer; c) a legitimação dos interesses dos agentes representativos do governo federal ligados ao desenvolvimento de políticas na área do esporte e d) a inexistência de mecanismos que assegurassem o reconhecimento e legitimação das "falas" que apontaram para demandas locais específicas que necessitavam ser enfrentadas.

Ao tecermos um olhar mais atento sobre a mudança na quantidade e na abrangência das proposituras geradas durante o I Ciclo de Conferências de Esporte do Estado do Amapá, torna-se possível perceber perdas de "falas" e geração de "invisibilidades" no transcorrer das etapas do evento, representando um potencial significativo de riquezas que se escoaram, visto que não houve garantias de sua integração no desenvolvimento de políticas locais.

A participação, entendida como diretriz balizadora na gestão, faz com que os integrantes da administração pública se vejam constantemente frente ao desafio de instituir e dinamizar mecanismos capazes de proporcionar a incorporação efetiva dos anseios da sociedade, tanto nos processos de planejamento, quanto nos processos de implementação e controle das ações de governo.

Sobre esta dimensão do fenômeno participativo, se debruçam possibilidades variadas de pesquisas e ações relacionadas com a inclusão das "falas" dos integrantes da sociedade nos processos de elaboração de políticas públicas. Dentre elas, sob a pers- 
pectiva do rito, podemos destacar a analise das peculiaridades e similaridades das dinâmicas ritualizadas no desenvolvimento de conferências consultivas e/ou deliberativas, tendo como ponto central o exercício do "poder dos fracos" e sua relação com produtos e consequências geradas pelo rito. Sob a perspectiva do processo, vale o destaque sobre o estudo, criação e experimentação de mecanismos formais e informais, que possibilitem tanto o encaminhamento de todas as demandas específicas identificadas para estruturas locais possuidoras de poder público deliberativo, quanto a ampliação e fortalecimento da malha social que se incorpora nos mais variados canais de participação.

É no estabelecimento de garantias de incorporação das "falas" daqueles que integram os processos participativos, que se denota a real preocupação em possibilitar efetivas construções coletivas de políticas públicas. Desta forma, faz-se necessário, nos processos participativos com formatação similar ao Ciclo de Conferências realizado no Estado do Amapá, que sejam criados mecanismos capazes de proporcionar 0 aproveitamento real (e não decorativo) dos posicionamentos apresentados pelos agentes representativos da sociedade na construção da gestão pública local, servindo como estratégias de resgate de "falas" e de "visibilidades perdidas".

\section{REFERÊNCIAS}

AM APÁ, Governo do Estado. Relatório da 1ạ Conferência Estadual do esporte do Amapá: metodologia utilizada para gerar as proposições encaminhadas para o M inistério do Esporte. Macapá-AP: Departamento Estadual do Desporto e Lazer, 2004. ARAÚJO, Silvana Martins de. Conferências Nacionais de Esporte: o debate sobre 0 controle social. In: JORNADA INTERNACIONAL DE POLITICAS PÚBLICAS, 6.,2013, São Luz. Anais... São Luiz-MA: Programa de Pós-Graduação em Políticas PúblicasUniversidade Federal do Maranhão-UFMA, 2013. p.1-10. Disponível em: বttp://www.joinpp.ufma.br/jornadas/joinpp2013/ >Acesso em: 18 abr. 2014.

BARDIN, Laurence. Análise de Conteúdo. Lisboa: Edições 70, 1979.

BOURDIEU, Pierre. A representação política: elementos para uma teoria do campo político. In: . 0 poder simbólico. Rio de Janeiro: Bertrand Brasil, 2007. p. 163207. 216, jan.-jul. 2011.

. 0 campo político. Revista Brasileira de Ciência Política, Brasília, n. 5, p.193BRASIL. Decreto no 2.574 de 29 de abril de 1998. Regulamenta a Lei no 9.615, de 24 de março de 1998, que institui Normas Gerais sobre Desportos e dá outras proviências. Brasília: Congresso Nacional, 1998b. Disponível em: বhttp://www.planalto.gov. br/ccivil_03/decreto/D2574.htm>. Acesso em: 12 mar. 2014 .

. Decreto no 981 de 11 de novembro de 1993. Regulamenta a Lei no 8.672 , de 6 de julho de 1993, que institui Normas Gerais sobre Desportos. Brasília: Congresso Nacional, 1993b. Disponível em: বttps://www.planalto.gov.br/ccivil_03/decreto/ 
1990-1994/d0981.htm>. Acesso em: 12 mar. 2014.

. Lei no $\mathbf{8 . 6 7 2}$ de $\mathbf{6}$ de julho de 1993. Institui normas gerais sobre desportos e dá outras providências. Brasília: Congresso Nacional, 1993a. Disponível em: বttp:// www.planalto.gov.br/ccivil_03/leis//8672.htm>. Acesso em: 12 mar. 2014 .

Lei $\mathbf{n} \mathbf{9} \mathbf{9 . 6 1 5}$ de 24 de março de 1998. Institui normas gerais sobre desportos e dá outras providências. Brasília: Congresso Nacional, 1998a. Disponível em: বhttp://www.planalto.gov.br/ccivil_03/leis//9615consol.htm>. Acesso em: 12 mar. 2014 .

. Lei no 9.981 de 14 de julho de 2000. Altera dispositivos da Lei no 9.615 , de 24 de março de 1998, e dá outras providências. Brasília: Congresso Nacional, 2000. Disponível em: বhttp://www.planalto.gov.br/ccivil_03/leis/L9981.htm>. Acesso em: 12 mar. 2014.

Portaria Ministerial no 13 de 03 de fevereiro de 2004. Regulamenta a Lei no 9.615, de 24 de março de 1998, que aprova o Regulamento Geral da Conferência Nacional do Esporte e as normas básicas de sua primeira reunião. Brasília: Ministério do Esporte, 2004. Disponível em: «ttp://portal.esporte.gov.br/conferencianacional/por tariaN1303022004.jsp>. Acesso em: 12 mar. 2014.

CASTELAN, Lia Polegato. As Conferências Nacionais do Esporte na configuração da política esportiva e de lazer do governo Lula (2003-2010). In: CONGRESSO BRASILEIRO DE CIÊNCIAS DO ESPORTE, 17, 2011, Porto Alegre. Anais... Porto Alegre: Colégio Brasileiro de Ciências do Esporte-CBCE, 2011. p.1-10.

ESPORTE, lazer e desenvolvimento humano: Documento final. I Conferência Nacional de Esporte. Brasília-DF: M inistério do Esporte, 2004.

GALINDO, Alexandre Gomes, MORAES, Rui Sebastião da Cruz. Analise dos resultados obtidos no 1 ํㅡㄹ Ciclo de Conferências do Esporte no Estado do Amapá: subsídios iniciais visando à elaboração de políticas públicas para o esporte e o lazer. Revista Cinergis, Universidade de Santa Cruz do Sul-UNISC, Santa Cruz do Sul, v. 5, n. 2, p.9-28, jul.-dez. 2004.

GENNEP, Arnold Van. Os Ritos de Passagem. Petrópolis: Editora Vozes, 1977. ROCHA, Roberto. A gestão descentralizada e participativa das políticas públicas no Brasil. Revista Pós Ciências Sociais. Programa de Pós-Graduação em Ciências Sociais da UFM A, São Luis-M A, v. 6, n. 11, p.41-57, 2009.

SOUZA, Marcelo Lopes de. A cidade, a palavra e o poder: práticas, imaginários e discursos heterônomos e autônomos na produção do espaço urbano. In: CARLOS, Ana Fani Alessandri; SOUZA, Marcelo Lopes de; SPOLITO, Maria Encarnação Beltrão. A produção do Espaço Urbano: agentes e processos, escalas e desafios. São Paulo: Contexto, 2011. p. 147-166.

TERRA, Alessandra Matos; BRANDÃO, Henrique Cândido; FLAUSINO, Michelle da Silva; M ASCARENHAS, Fernando. As Conferências Nacionais do Esporte: avanços e limites na construção das políticas públicas de esporte e lazer. In: CONGRESSO BRASILEIRO DE CIÊNCIAS DO ESPORTE, 16.,2009, Salvador. Anais... Salvador-BA: Colégio Brasi- 
leiro de Ciências do Esporte-CBCE, 2009. p.1-11.

TUBINO, Manoel. $\mathbf{5 0 0}$ anos de legislação esportiva brasileira: do Brasil-Colônia ao início do século XXI. Rio de Janeiro: Editora Shape, 2002.

TURNER, Victor W. 0 processo ritual: estrutura e antiestrutura. Petrópolis: Editora Vozes, 1974.

Artigo recebido em 24 de outubro de 2015.

Aprovado em 19 de agosto de 2016. 